\title{
A Rare Case of Transitional Cell Carcinoma of Ovary: Case Report and Review of Literature
}

\author{
${ }^{1}$ TS Anisha, ${ }^{2}$ Ajay K Sahu, ${ }^{3}$ Jyothi A Raj, ${ }^{4}$ BM Rupakala, ${ }^{5} \mathrm{M}$ Gautham, ${ }^{6} \mathrm{PS}$ Sharmila
}

\begin{abstract}
Introduction: Transitional cell carcinoma (TCC) of the ovary is a rare and recently recognized variant of epithelial ovarian cancer. It has been described as primary ovarian carcinoma with definite urothelial features, without benign, metaplastic, and/or proliferating Brenner tumor (BT) identified.
\end{abstract}

Case report: A 60-year-old lady presented with low back pain, growing abdominal mass, and loss of weight since 15 days. Magnetic resonance imaging (MRI) of abdomen showed a large ill-defined heterogeneous lesion with solid and cystic components. Beta human chorionic gonadotropin ( $\beta-\mathrm{hCG}$ ) and carcinoembryonic antigen (CEA) levels were raised. Surgery was performed and primary TCC of ovary was reported on histopathology.

Conclusion: Recognition of such tumors is important because of their rarity, favorable response to chemotherapy, and improved patient survival.

Keywords: Histopathology, Ovary, Transitional cell carcinoma.

How to cite this article: Anisha TS, Sahu AK, Raj JA, Rupakala BM, Gautham M, Sharmila PS. A Rare Case of Transitional Cell Carcinoma of Ovary: Case Report and Review of Literature. J Med Sci 2017;3(3):82-85.

Source of support: Nil

Conflict of interest: None

\section{INTRODUCTION}

Transitional cell carcinoma of the ovary is a recently recognized subtype of ovarian surface epithelial cancer, the pure form accounting for only $1 \%$ of surface epithelial tumors. ${ }^{1}$ It has been described as a primary ovarian carcinoma arising directly from the pluripotent surface epithelium of the ovary and from cells with urothelial potential, with definite urothelial features but no benign, metaplastic, and/or proliferating BT identified..$^{2-4}$ Recognition of

\footnotetext{
${ }^{1,5}$ Assistant Professor, ${ }^{2}$ Postgraduate Student, ${ }^{3,4}$ Professor ${ }^{6}$ Professor and Head

${ }^{1-3,6}$ Department of Pathology, RajaRajeswari Medical College \& Hospital, Bengaluru, Karnataka, India

${ }^{4}$ Department of Obstetrics and Gynecology, RajaRajeswari Medical College \& Hospital, Bengaluru, Karnataka, India

${ }^{5}$ Department of Radiology, RajaRajeswari Medical College \& Hospital, Bengaluru, Karnataka, India

Corresponding Author: Jyothi A Raj, Professor, Department of Pathology, RajaRajeswari Medical College \& Hospital Bengaluru, Karnataka, India, e-mail: jyoki255@yahoo.co.in
}

such tumors is important because of its rarity, favorable response to chemotherapy, and improved patient survival.

\section{CASE REPORT}

A 60-year-old lady presented with low backache, pain abdomen, abdominal mass, and loss of weight for 15 days. Magnetic resonance imaging of abdomen and pelvis showed a large, irregular, lobulated, and ill-defined, heterogeneous lesion with solid and cystic components. The mass measured $14 \times 13 \times 12 \mathrm{~cm}$. The ovaries could not be seen separately. The mass was seen extending up to the anterior abdominal wall, indenting the bladder and displacing the rectum. Bladder was uninvolved. A radiologic diagnosis of ovarian malignancy was suggested (Fig. 1).

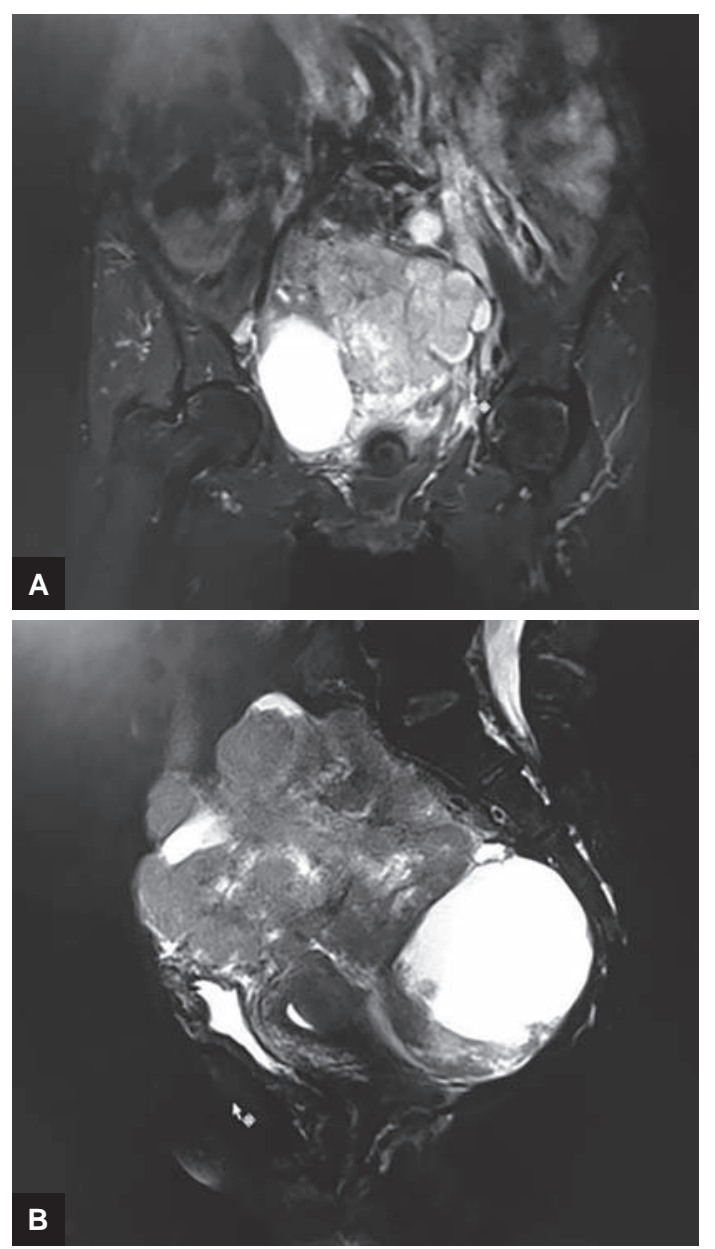

Figs 1A and B: (A) Coronal; and (B) sagittal planes: TCC of ovary. MRI showing a large, irregular, lobulated, and ill-defined heterogeneous lesion with solid and cystic components 
Routine biological tests were within normal limits. Initial investigation of tumor markers before surgery showed serum CA-19.9 (5.2 U/mL; normal, 0-27 U/mL) and alfa-fetoprotein levels within normal range $(1.16$ $\mathrm{IU} / \mathrm{mL}$; normal 0.5-5.5 IU/mL); $\beta$-hCG $(7.84 \mathrm{mIU} / \mathrm{mL}$; normal $<5.3 \mathrm{mIU} / \mathrm{mL})$ and CEA levels $(4.9 \mathrm{ng} / \mathrm{mL}$; normal $<3.80 \mathrm{ng} / \mathrm{mL}$ ) were minimally elevated. She underwent surgery with a provisional diagnosis of malignant ovarian tumor. A small amount of ascites (about $100 \mathrm{~mL}$ ) in the pelvic cavity was found intraoperatively. Surgical staging procedures including total abdominal hysterectomy, bilateral salpingooophorectomy, infracolic omentectomy, and pelvic lymph node dissection along with appendicectomy were performed.
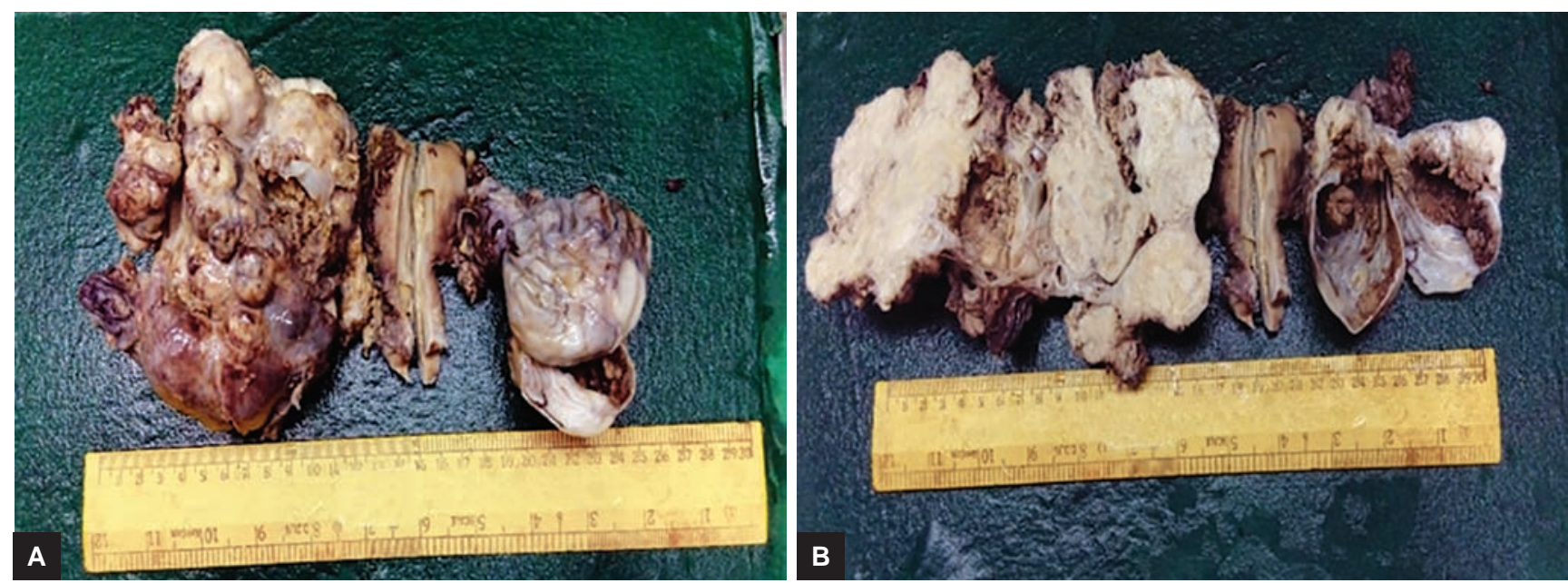

Figs 2A and B: The TCC of ovary. External surface of both ovaries shows capsular breach and papillary excrescences. Cut surface was solid with cystic and necrotic areas

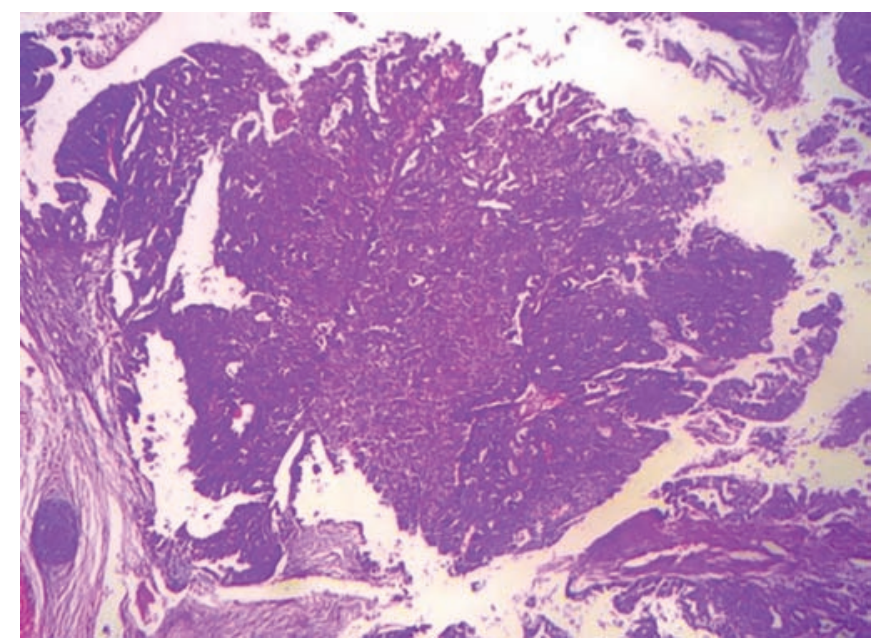

Fig. 3: The TCC of ovary. Photomicrograph showing transitionaltype epithelium lining thick blunt papillae (hematoxylin and eosin, $4 \times$ )

\section{MORPHOLOGY}

\section{Gross}

The right ovarian mass measured $12 \times 9 \times 6 \mathrm{~cm}$. External surface showed capsular breach and papillary excrescences. Cut surface was predominantly solid, with cystic and necrotic areas. Left ovary was also enlarged, measuring $7.5 \times 5.5 \times 3 \mathrm{~cm}$. External and cut surfaces showed features similar to the right ovary (Fig. 2).

\section{Microscopy}

Microscopy from right ovarian mass showed an infiltrating malignant neoplasm, composed of pleomorphic transitional type epithelium lining thick blunt papillae, with prominent intracystic projections and smooth luminal borders (Figs 3 and 4). The cells were also seen

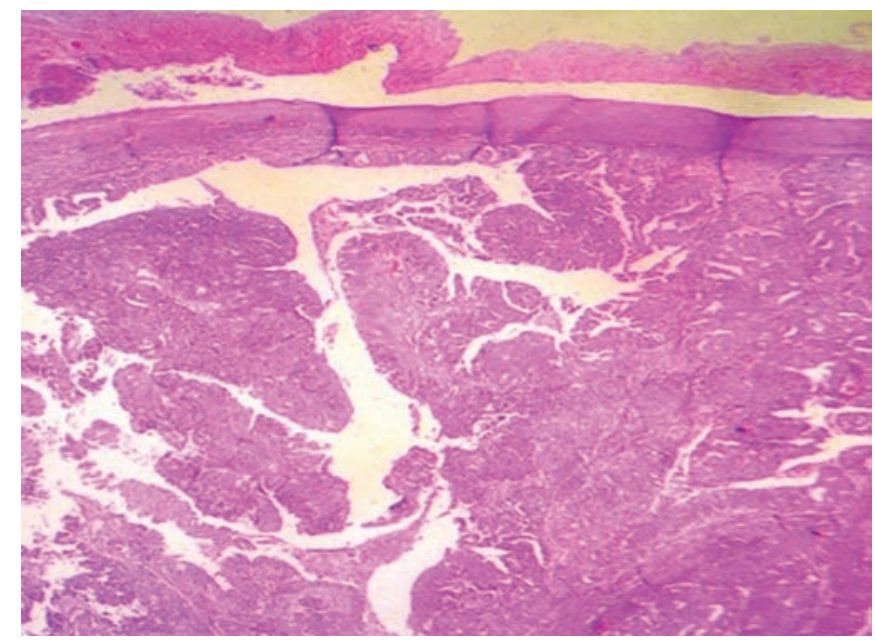

Fig. 4: The TCC of ovary. Photomicrograph showing papillary formations of tumor cells within intracystic spaces, with smooth luminal borders (hematoxylin and eosin, $4 \times$ ) 


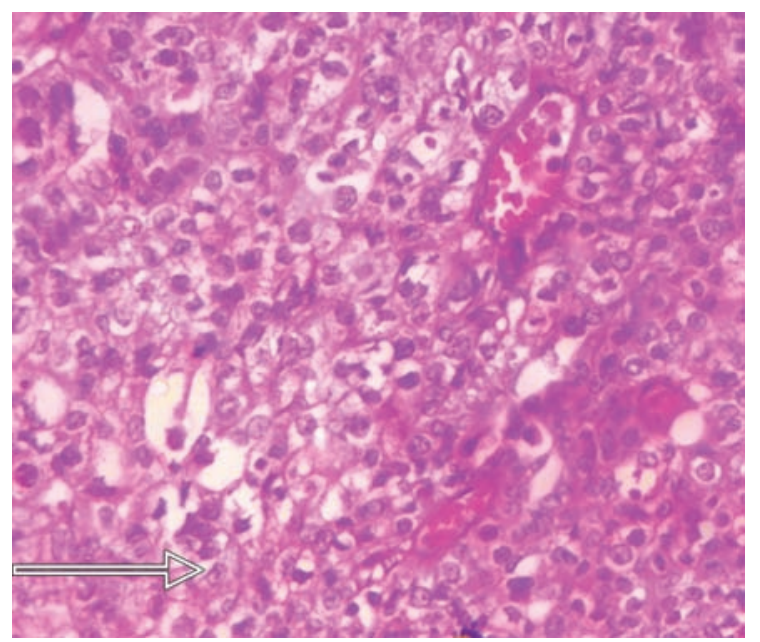

Fig. 5: The TCC of ovary. Photomicrograph showing tumor cells with grooved nuclei (arrow; hematoxylin and eosin, 40×)

arranged in nests and sheets. The tumor cells were round to polygonal with clear to granular cytoplasm, large vesicular or grooved nuclei with high $\mathrm{N}: \mathrm{C}$ ratio, coarse chromatin, and prominent nucleoli (Fig. 5). Microspaces lined by multilayered neoplastic transitional cells were seen amidst the solid sheets. There was no BT component or prominent stromal calcification. Left ovary, both tubes and appendix showed tumor (Fig. 6), with similar morphology as described earlier.

\section{DISCUSSION}

Primary TCC of the ovary was first described by Austin and Norris in 1987, as a tumor with definite urothelial features, but no benign, metaplastic, and/or proliferating Brenner component. ${ }^{1,5}$ It is the pure form in $1 \%$ and predominant element in $5 \%$ of ovarian surface epithelial carcinomas. The great majority of TCCs occur in 50- to 70-year-old women. ${ }^{4}$ Its clinical features are similar to other malignant ovarian tumors and are bilateral in $15 \%$ of cases.

\section{Differential Diagnosis}

Primary TCC can closely mimic metastatic tumors and the two are differentiated on the usual clinical, gross, and microscopic criteria.

Distinguishing primary TCC from other poorly differentiated surface epithelial carcinomas in the ovary can be a diagnostic dilemma and is mostly done based on morphologic criteria: Broad papillae lined by cells, some of which may resemble transitional cells, thick undulating bands, and microspaces. It lacks the prominent stromal calcification characteristic of BTs. ${ }^{5}$

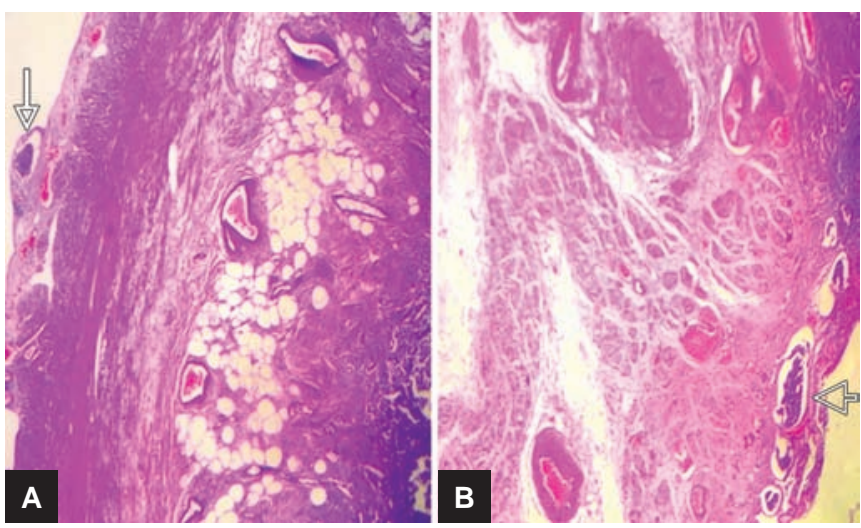

Figs $6 \mathrm{~A}$ and $\mathrm{B}$ : Photomicrograph shows tumor deposits in fallopian tube: (A) Appendix; and (B) (arrows; hematoxylin and eosin, 4x)

\section{Immunoprofile}

Recent studies on the comparison of immunophenotypes between BT and transitional cell tumors of the ovary and urothelial carcinoma have yielded conflicting results. ${ }^{1,4,6,7}$

Transitional cell carcinoma, in general, has an immunoprofile similar to other surface epithelial carcinomas of ovary. It expresses CK7, but is negative for urothelial markers CK13, CK20, or uroplakin III.

\section{CONCLUSION}

Primary TCC of ovary is a rare and recently described subtype of epithelial ovarian tumors. They resemble TCC of the urinary bladder on histology, but not in immunoprofile. Histopathology remains the first tool in their diagnosis and in their distinction from other closely related tumors, as in the present case. Surgical resection is the primary therapeutic approach. Greater chemosensitivity and better 5-year survival rates make their recognition relevant for treatment.

\section{REFERENCES}

1. Chandanwale SS, Kamble T, Mishra N, Kumar H, Jadhav R. A pure pimary transitional cell carcinoma of the ovary: a rare case report with literature review. Int J Appl Basic Med Res 2016 Apr-Jun;6(2):140-143.

2. Ichigo S, Takagi H, Matsunami K, Murase T, Ikeda T, Imai A. Transitional cell carcinoma of the ovary (Review). Oncol Lett 2012 Jan;3(1):3-6.

3. Manoharan M, Manian S, Ganesh D. Transitional cell carcinoma of the ovary: a rare case report. IJCRR 2014 Apr;6(7): 74-78.

4. Lee KR.; Russell P.; Tavassoli FA.; Buckley CH.; Prat J.; Pisani P.; Dietel M.; Schwartz P.; Gersell DJ.; Goldgar DE.; et al. Tumours of the ovary and the peritoneum. Chapter 2. In: Tavassoli FA, Deville P, editors. World Health Organisation Classification of tumours of the breast and female genital organs. Lyon: IARC Press; 2004. p. 113-202. 
5. Ingin RJ, Andola SK, Zubair AA. Transitional cell carcinoma of the ovary: case series and review of literature. J Clin Diagn Res 2014 Aug;8(8):FD07-FD09.

6. Gilks B.; Young RH.; Clement PB. Ovarian epithelialstromal tumors. Chapter 54. In: Mills SE Sr, editor. Sternberg's diagnostic surgical pathology. Vol. 2. 6th ed.
Philadelphia (PA): Lippincott Williams and Wilkins; 2015. pp. 5904-5990.

7. Zaloudek C.; $\mathrm{Ng}$ BW. The ovary and fallopian tube. Chapter 39. In: Silverberg SG, editor. Silverberg's principles and practice of surgical pathology and cytopathology. Vol. 2. 4th ed. Philadelphia (PA): Churchill Livingstone; 2006. pp. 1987-2061. 